\title{
The effect of the scale of mosques and the relationship with passenger access in Islamic cities in the Safavid age
}

\author{
Maliheh Ahmadi \\ Department of Architecture, Shahr-e-Qods Branch, \\ Islamic Azad University, Tehran, Iran
}

\begin{abstract}
The mosque is regarded as an essential part of Islamic cities. Recognizing the impact of mosques on Islamic cities and how they influence people's life is of great importance. The Safavid era (18th to 20th century) is regarded as a milestone in urban development in Iran. The main object of this paper is to examine the influence of the scale of mosques, and how easy was it for pedestrians to access those mosques in Safavid eras. In light of the peculiar status of the city of Isfahan among other Islamic cities in Iran; and in light of the fact that art and religion reached their climax at the seat of the government during the Safavid eras, we might find it useful to explore the atmosphere that dominated over the mosques in that city in those eras. Based on their function and location, on city, district, ward, scale, they have had their own throughways, and accesses with various entrances. This paper is based on the assumption that with respect to accessibility, function and structural organization, all mosques were not in identical situations. With respect to dimensions, capacity, building to open space ratio, accessibility, locality, and their function, this research concludes that the mosques in Isfahan are divided into 3 major categories. In addition to particular criteria and distinguishable features of mosques that were mentioned above, study of Safavid era mosques reveals that there is an identical characteristic which is common among all of the Safavid era mosques. This paper highlights some of those common features and makes special recommendations.

Keywords: mosques, scale, passenger access, Islamic cities.
\end{abstract}




\section{Introduction}

\subsection{Importance of the mosque in Islamic cities}

Mosque (Masjed) is a main element in Islamic cities. The mosque is a symbol of an Islamic city with different functions as sometimes governments have relied on the mosque for showing their powers (Boroumand Saleh [1]). In early Islam, main social activities were performed in the mosque which operated as a religious, political, educational, military and other center. An obvious example is Masjed Alnabi (Dinparvar [2]). On the other hand, according to Holy Islam, emphasizing on the presence of Muslims in the mosque for praying within determined hours, five times per day, the necessity of access to the mosque is an urban requirement. Recognizing the effects of the mosque on an Islamic city and its performances in compliance with the location in the city bear a special importance.

\subsection{Goals}

According to their location and performance in the city, mosques have different relationships with their surroundings and the various passages, accesses and gates in the city, region, district and county, with equestrian and pedestrian access depending on the scope of their functions (Talebi [3]).

The Safavid reign (15th to 17th centuries) is considered as a touchstone period in Islamic urban development, and the main goals of this paper include the recognition of interrelations of the scale of mosques and their pedestrian access in that reign, the use of their practical aspects and generalizing on the contemporary period.

\subsection{Research methodology}

The method of this research is comparative and analytical, using library resources in this field. Having the plan of the locations of different mosques of Isfahan in the Safavid reign, I have tried to categorize them with various functions and find a system in the access roads.

It seems that the result of this study may consider Isfahan mosques in several separate groups (3-5 groups) in terms of scale and function concerning spatial location and pedestrian access roads.

\section{Classification of mosques in Isfahan in the Safavid reign}

According to the unique status of Isfahan among Islamic cities and the fact that art and religion were highly flourishing in the middle of the Safavid dynasty, we may find a spatial system between the mosques of this city.

Isfahan is the third greatest Iranian city, located in a semi-temperate region in the center of Iran. 
When selected as the capital for the second time, Isfahan was highly developed, as it has even today preserved its previous magnificence. There are various historical buildings in the city, some of which have been registered in UNESCO as historical heritage. Isfahan was selected the Cultural Capital of the Islamic World in 2006. This city is proud of its fine Islamic architecture and many beautiful boulevards, roofed bridges, castles, mosques and unique minarets. It causes Isfahan to be called Half of the World in Iranian culture. Naghsh Jahan Square is one of the greatest squares in the world; an excellent example of Islamic architecture registered by UNESCO as a world heritage site (Ganjnameh [4]).

From the early flourishing of Islam, the mosque has been the most important and original center of meetings as the presence of a General Mosque is a symbol of urbanization and the basis of distinguishing urban society and other communities (Soltanzadeh [5]).

The importance of the mosque was added by the appearance of Safavids when the mosque was used as a symbol of ideals and the recognizing factor of Shiite. Therefore, many mosques were constructed in the city or the old ones were reconstructed, and mosques were paid attention not only in the city and the center but also in each county, even each alley.

The mosque is placed almost solely and sometimes combined with other functions: it is occasionally integrated with a school as a center of science education, and their functions are separated skillfully within a unit. It might be combined with Imamzadeh and graves of scientists and clergymen. The functional and spatial diversity distinguishes the mosque from other general urban elements and gives it a typical position in urban life (Dinparvar [2]).

In a study of Safavid mosques and according to the attention to measures such as dimensions and sizes, area, ratio of structure to open space, access roads, location in city and surrounding functions, the mosques are categorized in three main groups.

\subsection{1st group mosques}

The mosques having a function in the city formed around the main center of the city, being a place for not only praying and religious ceremonies but also for performing governmental affairs and formalities. The general mosque played such a role before Safavids, and Imam and Sheikh Lotfollah mosques in the Safavid dynasty. Such mosques not only were separated into two or more bodies of adjacent structure but informed their presence and location in the city by physical determination in a body selected main gate. The considerable point in Imam and Sheikh Lotfollah mosques is the method of masterly integration of the body of market around the square and main gate of the mosque (Tavasoli [6]).

Main spaces around the mosque included the central square of the city, governmental location and market. The square was rectangular $(165 \times 510 \mathrm{~m}$ in dimension) with a vast and open horizon to the sky, and connecting sky and earth. The religious rituals, national ceremonies and other urban plays were executed in this location. 
The frontier site of the Imam Mosque, which is a structure itself, has a statue to welcome the outside population to safety, security and reinforcement. Two frames in two sides of the gate are in the form to place the prayer stands in. Further away, a considerable perspective which sometimes seems ethereal due to its brilliant blue color, it is fully dominant in the square and, unlike the majestic palace of the King, shows the substantial dominance of religion on materialistic power and principal importance of religion in urban life.

Through the frontier site, one enters an excellent corridor that has been a characteristic of Iranian historical buildings from ancient periods. It is round, without any direction, being a heel on which the basis of the building rotates. The corridor opens to the long room of the northern balcony through whose darkness one may suddenly see the light yard. On that side, the yard moves to a vast site: a gate of another world of magnificence and authority.

Long and large rooms, excellent and brilliant crosses and fast curves show spaces freely interrelated to each other to mihrab like waves. People praying may see each other when standing to pray or attending a connective space solely. Mutual awareness and common worship is the main center of Islam, and here the building serves religion (Mosque Architecture [7]).

On the other hand, the ratio of mosque yard to the area is more than $40 \%$ in such mosques (figures 1-6).

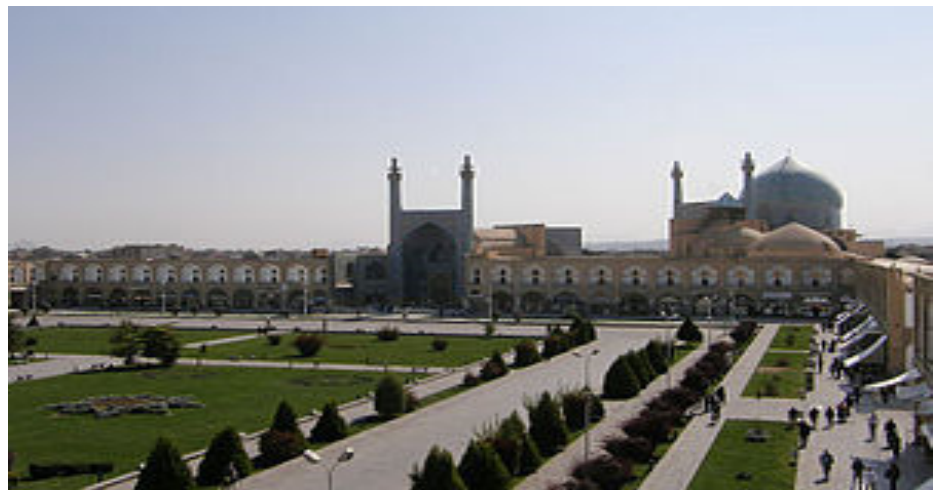

Figure 1: $\quad$ Imam Square.

\subsubsection{Importance and elements of the 1st group mosques}

A general mosque in Islamic cities, being usually unique, is always located at the heart center of the city, extended by a market in two or more directions, and surrounded by social institutes such as the court, caravansary, inns for passengers, places for poor people, hospital, convent, bathrooms and schools (Hataminejad and Nikpour [8]). In the Isfahan General Mosque extended by some attachments during different reigns, connections have been changed to the closed sites (corridors), preparing humans for confronting special spatial events magnificently expected in the yard after passing bedchambers and a line of columns. The diversity of adjacent spaces, each passing way increases the attraction and absorption. One of the gates to the general mosque is on 

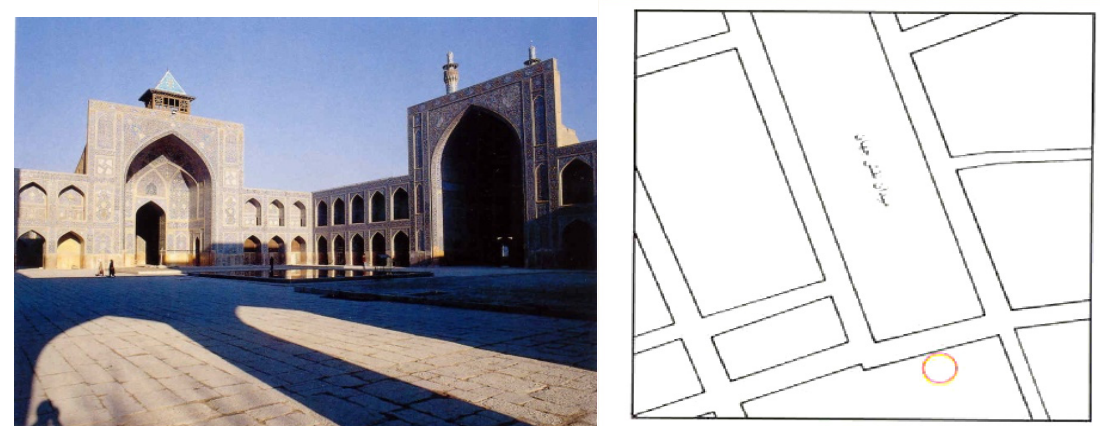

Figure 2: $\quad$ Imam Mosque, Naghsh Jahan Square.
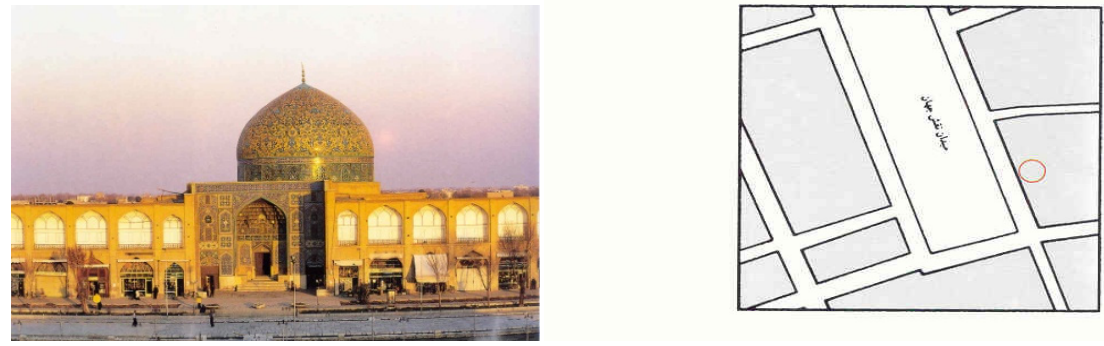

Figure 3: $\quad$ Shaikh Lotfallah Mosque Naghsh Jahan Square.
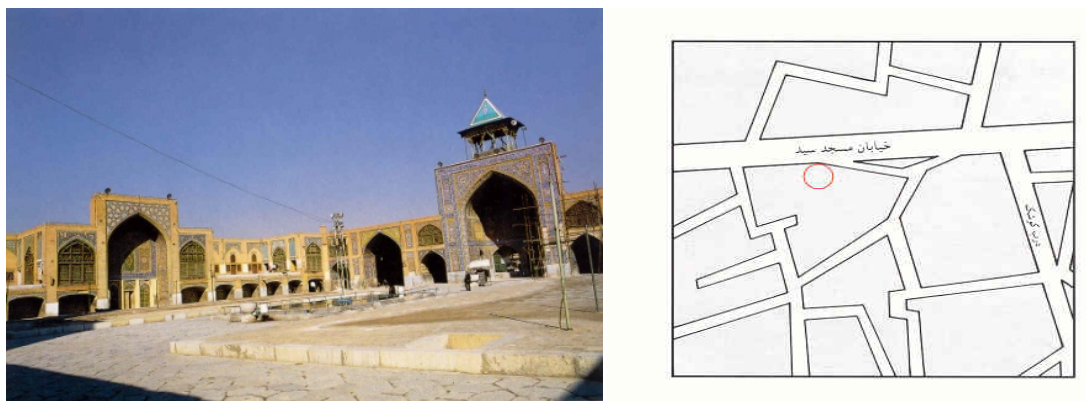

Figure 4: $\quad$ Shaikh Lotfallah Mosque.

the eastern side entering the mosque through an adjacent way of a small yard, making a combination of semi-open and closed spaces. Another parallel gate, being a main gate from the market, there are bedchambers of a line of their columns in the vicinity.

In the Imam Mosque, after passing the semi-open site of entry, a closed space is expected that makes it possible to access the open yard by connection of two adjacent closed spaces, while the perspective of yard is observable through the semi-open space of a balcony on the opposite side. 
In Seyyed Mosque which is also a school, the entrance of the mosque is via long and closed corridors, moving to a yard by some curves. Such a way gives a sense of entering a space of silence and tranquility as important and increases the spirituality.

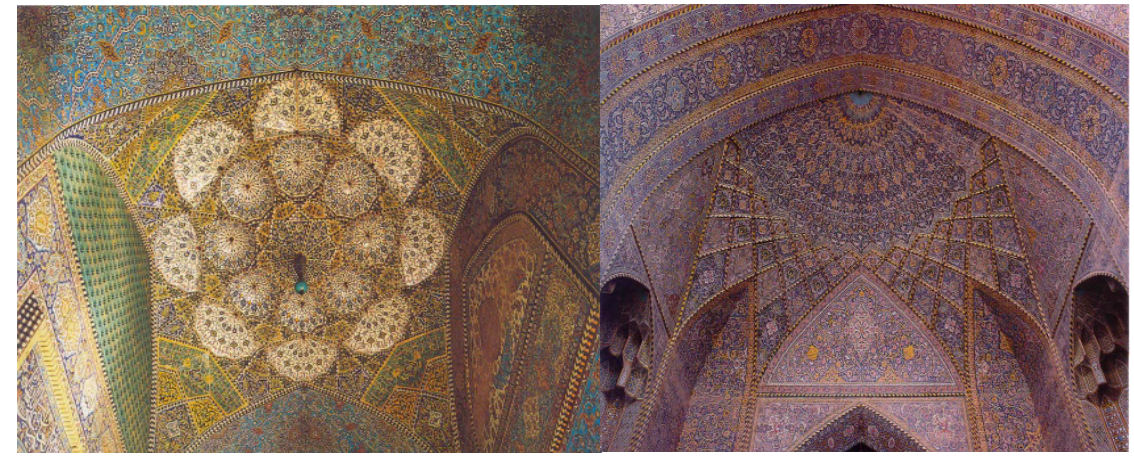

Figure 5: Seyyed Mosque.

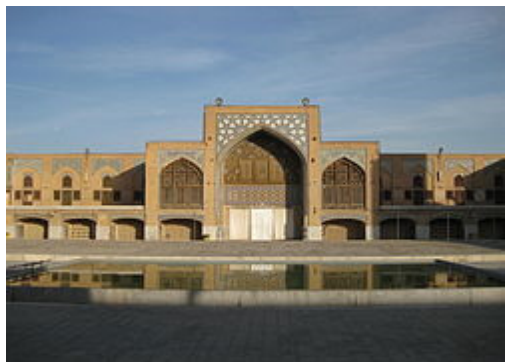

Figure 6: $\quad$ Seyyed Mosque.

\subsection{2nd group mosques}

The mosques with a function beyond the county: the mosque has performances other than being place for prayer. It is easier to access and there are two or more connecting elements to enter the mosque site. According to the higher
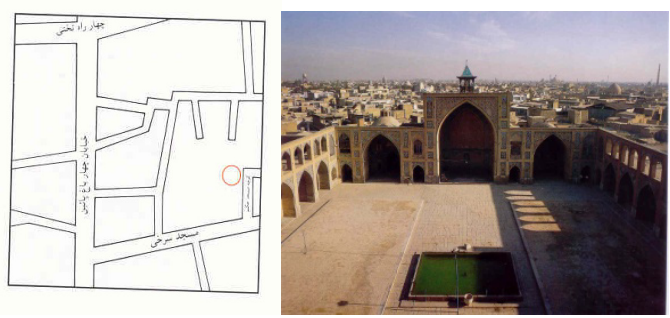

Figure 7: Hakim Mosque. 
importance of its functions, the importance of the internal yard increases too. The number of elements making it possible to connect the internal space in any side increases. Some examples of the Hakim Mosque clearly show the use of internal space of the mosque as an urban space and easy access from any side. Such mosques were usually constructed by famous persons.

In this case, the connection elements are a collection of semi-open and closed spaces with typical characteristics.
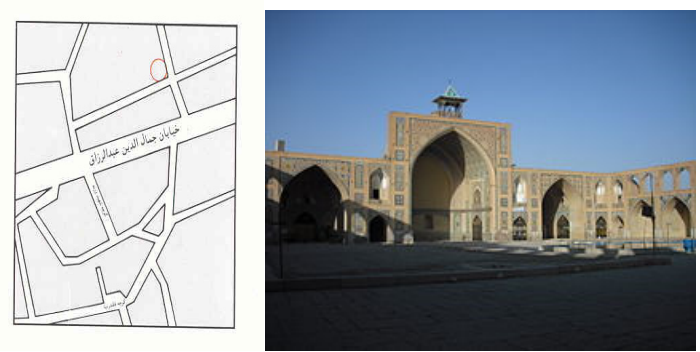

Figure 8: Jamaladdin Abdolrazzagh Street Haj Mohammad Jafar Abadehee Mosque.

In these mosques, the ratio of yard to the area is about 20-40\%. Main spaces adjacent to the mosque site included a market, lodges, caravanserais and bathroom (figures 7-8).

\subsection{3rd group mosques}

Mosques whose main function is praying and religious ceremonies and whose scope of function is limited to the residential alley or market including a special occupation. They are spread in the different counties and recognized as the place for prayer and worship for people in the county. In this case, the mosque is fully integrated with the adjacent site and easy to access through a gate in an adjacent way. After passing a mainly closed space or a collection of semi-open and closed spaces, one enters the mosque (figure 9).

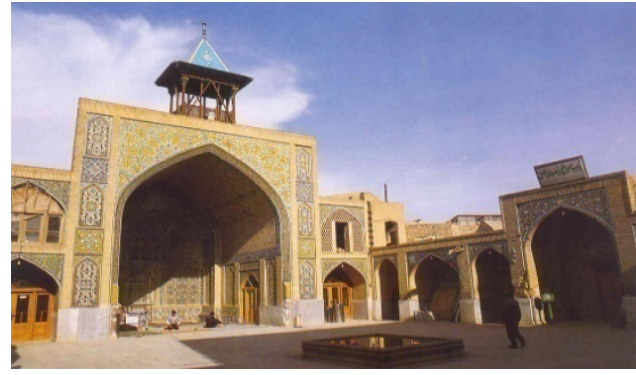

Figure 9: $\quad$ Haj Mohammad Jafar Abadehee Mosque. 
Particularly placed in the body of the market, they do not even have an internal open space but the main space around the mosque includes residential houses as they have limited internal open space.

In such mosques, the ratio of yard to area is near to $20 \%$.

There are a lot of such mosques in all counties throughout the city whereas the first two groups of mosques are mainly located in the central part and main roads of the city (figure 10 ).

Images of the important 3rd group mosques will be presented.

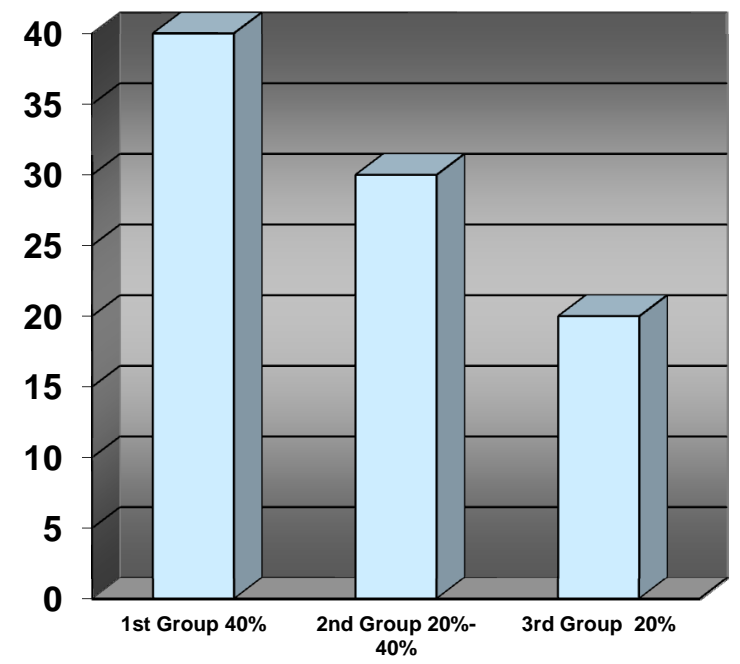

Figure 10: Ratio of yard to area in mosques.

According to the mentioned items and by modeling the mosques' construction method in the past and offering complementary opinions, the mosques of today's cities may be divided into the following items with regard to the urban divisions:

- $\quad$ Local religious places: small mosques, small house of worship;

- Regional religious places: middle mosques and middle house of worship;

- District religious places: great mosques and religious centers;

- Zonal religious places: religious complexes, house of missionaries and great religious centers;

- Urban religious places: general mosques, main mosque of the city, Imamzadeh, Mosalla, temples;

\section{Common elements in Safavid mosques}

In addition to the critical measures and elements of mosques already mentioned, the following collection of common characteristics and specifications of Safavid 
mosques was observed and the results are presented in the framework of determined advice.

\subsection{The mosque as a symbol}

In the Islamic culture, Symbol is an important subject. Urban studies performed in the urban communities represent that urban symbols are factors regularly present in the minds of citizens. Therefore, mosques of a city shall be imagined in the citizens as they remember some spiritual concepts and undertake their virtual guidance, playing role in the whole of the city (general mosque) and counties (local mosques) as considerable symbols (Minarat Articles [9]).

\subsection{Network structure of the situation of mosques}

The network structure of Safavid mosques may be shown in a diagram including a number of the 2nd group around the 1st group mosques in the urban regions. Then, the 3rd group mosques are placed into counties in a scattered way while building a network with the 2nd group mosques. Therefore, this harmonic structure can be used for finding the location of mosques in today's cities. This specific method of mosque location requires a typical harmony in drawing the sky line of the city.

\subsection{The mosque as an identity}

During Safavids, mosques were one of the important elements of a city's identity. Today, Muslim cities are an incomplete repetition and imitation of western cities. However, we shall survive the identity of Muslim cities through planning and thinking design again and again: starting with the mosque. Today, the identification of Muslims' belongings is more important and vital than in the past, and imitation of western models in the long constructions and highways gorging the body of the city, and priority to the cars in the cities will aggravate the conditions (Mosque Architecture [10]).

\subsection{The mosque as the main center of an Islamic city}

In past Islamic cities, the mosque enjoyed a special position in the center of cities, districts and counties. Therefore, the mosque shall be a center so that if one sees a mosque, he understands to access the main urban spaces and functions (meeting his different requirements) around it under some regulations remaining from the successive periods, though unwritten, in an orderly and regular hierarchy.

\subsection{The mosque: the dominant body}

In Safavid cities, the dominant body of the city was the mosque. Thus, its volume, form and shape should be developed and dominant on the urban body and that which shows materialism and the physical world. 
What seems important in this case is not just the external form and physical domination (in the one hand) but the negative and dangerous effects of long and glorious structures on the human soul and spirit.

\subsection{Spatial location discipline}

Spatial location discipline is a process of organizing spatial discipline to integrate separate spatial units to each other. It occurs by putting each unit into a more extensive whole in which the mutual dependency of elements are organized in a close relationship in order to keep or reinforce any element than the whole of the organization.

Sensitivity to the replacement of the mosque concerning other elements of collection than the link of collections to each other and finally to a larger whole, that is the city, with the purpose of "Removal of Out-Selections" is a positive aspect of such a spatial organization on a macro level helping to keep integration of the mosque with the total structure of the city.

This characteristic may be used in urban planning.

Figure 2 - the mosque is an element of the continuous structure of the market, in an integrated whole including the units of connected distinguishing functions than in a larger total whole. This spatial connection method requires a close relationship and mutual dependency of the mosque and other elements preventing separation, out-selection and the solitary location of the mosque from other public units of the city.

\subsection{The mosque: the junction of religion and art}

The mosque is a space and a place which raises Islamic art and architecture to the top. Therefore, there are many collections of art serving the mosque with a significant message. In the art of mosque construction, the concepts of internal and external space, vertical and horizontal lines, curves and manuscripts, form, symmetry, color, discipline, harmony, rhythm, combination of light and water are important. The construction of the vault, mihrab, posy, columns, pulpit, minaret, bedchambers and other elements show all the relationships of God and creatures, encouraging the human mind to think of the spiritual world through magnificence and order (Zargar [11]).

\subsection{Awareness of pedestrians in the direction of the mosque}

In the past mosques, movement to the mosque was a tramping, slow, meaningful and interesting movement to define the target.

Great scale and considerable distinguishing of the mosque body to the surrounding buildings as well as defined volumetric elements and some indices such as vault and minaret focused on the excellent presence of the mosque as an urban symbol deserving praise, making it possible to recognize the mosque in the far distance, helping the personal direction and informing one of movement to an important, spiritual and honorable place (Zargar [12]).

Special attention to the applied suitable mapping and in compliance with the activity of the mosque in the vicinity informed the passenger of the gradual 
achievement of getting to the mosque and strengthened the role of its symbols. By considering such thoughts in an organization of spatial specifications of the mosque and surrounding activities, the observer doesn't need to search for any identity boards on top of the mosque.

\section{Conclusion}

According to the role and importance of mosques in Islamic cities, the following total advice may be reached in finding location of mosques:

- $\quad$ Enjoying mosques in the structure of a city and conducting its growth;

- Developing diversity in design and harmonizing it to the surrounding texture;

- $\quad$ Observing a distribution model suitable to the religious functions in the city;

- Compatibility of the mosque and dependent elements in the improvement of the urban appearance and view.

\section{References}

[1] H. Boroumand Saleh, Article (City and Mosque) Mosque Architecture, Future Perspective, 2001.

[2] S. J. Dinparvar, Article of Mosque, Center of Islam, Mosque Magazine, No. 59, 2002.

[3] J. Talebi, Article (Mosque as Center of Social Unity), Mosque Architecture, 2001.

[4] Ganjnameh, Culture of Works of Iran Islamic Architecture, Isfahan Mosques, Documents and Researches Center of Faculty of Architecture and Urban Planning, 1996.

[5] H. Soltanzadeh, Formation of City and Religious Centers in Iran, 1975.

[6] M. Tavasoli, Abadi, 5th Year, No. 19, Article of Concept of Space in Sheikh Lotfollah and Naghsh Jahan Mosques, 1995.

[7] Mosque Architecture, Collection of Articles of Mosque Architecture Meeting, Past, Now, Future, University of Art, University College of Isfahan, December 1997.

[8] H. Hataminejad and A. Nikpour, Abadi, 20th Year, No. 66, Article of ReIdentification of Concept of City Center, 2010.

[9] Specialized Articles of Mosque, Minaret Information Center, Article of An Introduction to Recognition of Art and Traditional Architecture of Mosques, 2010.

[10] Mosque Architecture, Collection of Articles of Mosque Architecture Meeting, Past, Now, Future, 2001.

[11] Zargar, Guidelines of Mosque Architecture, Iran Architectural and Urban Planning Studies and Research Center, 2010.

[12] Zargar, Fundamentals of Mosque Design, Principles of Mapping, Mosque Design Studies and Research Center, Ministry of Housing and Urban Planning, 2004. 